\title{
Regenerative Development in Higher Education: Costa Rica's Perspective
}

\author{
Eduard Müller
}

\section{Introduction: How Did We Get to Where We Are?}

Our planet is in trouble: climate change, a consumer society that extracts more resources than what the planet can provide, a broken economic model, combine with politics gone wrong. We also have incredible power in communication technology, especially through social media. We have enormous capacity for data analysis, trending rapidly to data analytics and artificial intelligence (AI). However, we are not able to transform all this information and knowledge into wisdom, yet.

According to Wikipedia, "Wisdom or sapience is the ability to think and act using knowledge, experience, understanding, common sense, and insight. There appears to be consensus that wisdom is associated with attributes such as compassion, experiential self-knowledge, non-attachment and virtues such as ethics and benevolence."

The first sentence shows how far away we are from our true goal. We are officially undergoing the sixth planetary extinction, we have moved

\footnotetext{
1 "Wisdom," Wikipedia, January 15, 2018, https://en.wikipedia.org/wiki/Wisdom.
}

E. Müller $(\bowtie)$

University for International Cooperation, San José, Costa Rica

e-mail: emuller@uci.ac.cr

(C) The Author(s) 2018

N. W. Gleason (ed.), Higher Education in the Era of the Fourth Industrial

Revolution, https://doi.org/10.1007/978-981-13-0194-0_6 
from the Holocene to the Anthropocene. This is the best scientifically documented planetary extinction-we have all the science and know with great precision what we are doing wrong. The second sentence relies on intangibles which cannot be accurately measured and thus not very popular in traditional academic approaches. The acceleration of time, with changes happening so fast, has contributed to immediacy and ephemerality. Taking time to step outside of the daily rush and look at the broader perspective, beyond our immediate needs, has been downgraded in response to the urgency for action, and the competitiveness of human enterprise. Determining what went wrong at this point in history is probably impossible, especially since there are so many factors involved. This is precisely what brings me to my main argument: The reductionist approach to Western education is a key challenge!

\section{Reductionist Versus Holistic Approaches}

We can trace the origins of reductionist approach back to Socrates and Plato and the Socratic Dialogues which proposed that research should clearly identify one question, the Hypothesis, and focus on finding one answer. We could also invoke Aristotle with his 'Prior Analytics' or Descartes, whose scientific philosophy was based on the assumption that the material and spiritual realms of human existence were disconnected and, being the human mind separate from nature, enabled humans to control nature. We could also argue that it started with Isaac Newton, who was convinced that the universe was made up of bodies that behaved uniformly, following the laws of motion where interactions are limited to simple relationships related to the forces exerted between the bodies.

Whatever argument we choose, the reality is that the reductionist approach evolved based on the fact that a system could be understood by studying the individual components, which were literally, in some cases, dissected to death. This led to the establishment of disciplines, faculties and departments at our universities and to an ever-ongoing spree of specialization. This also affected the institutional frameworks, with separate entities being established to deal with environment, agriculture, economics, culture and so on. The belief prevailed that the best science is the one that describes the smallest detail and is published in the corresponding most prestigious peer-reviewed journal. The idea that interactions between components of a system can be more relevant than the components themselves, and that the end sum is greater than the sum of the individual components, was ignored. The thought that there can be something even 
greater that transcends systems such as consciousness was actively opposed and still remains mostly controversial in science.

\section{Systems Thinking}

A little less than 100 years ago, Ludwig von Bertalanffy started what we know today as systems thinking or systems theory. ${ }^{2}$ The concept of Ganzheitlichkeit, from Ganz - which stands for healthy, not hurt and complete or integral—can be translated to holism and according to Thomas Diesner is the consideration of a matter in the systemic integrity of all parts, as well as in all their properties and relationships. ${ }^{3}$ This has since influenced how higher education approaches system thinking. In the early 1980s, Robert Hart started working on applying Howard T. Odum's approaches in ecological systems to farms in Honduras and Costa Rica, using interdisciplinary approaches to learn from and optimize the interactions that take place within a productive system. Flows between the agroecosystems and between the farm and its surroundings were measured in energy units, biomass, labor or money. ${ }^{4}$ Decades later, attempts at defining systems thinking are still taking place ${ }^{5}$ while the great majority of our institutions, universities and curricula are still mostly disciplinary.

Complex problems such as global change, climate change or poverty require complex solutions. Individual disciplines cannot understand these complex issues and have proven completely unsatisfactory in providing solutions. All three are increasing after decades of academic and technical work. While trying to find better solutions, we have transitioned through multidisciplinary and interdisciplinary approaches, without great success in changing our development path. One of the difficulties is appropriate dialogue; often specialists from different disciplines lack a common language for even the most basic communication and understanding. Scientists, generally, have great difficulty simplifying their vocabulary to communicate with other stakeholders, especially groups like politicians or local communities.

${ }^{2}$ Thomas Diesner, Die Allgemeine Systemtheorie bei Ludwig von Bertalanffy. Eine Begründung interdisziplinärer Wissenschaftspraxis (Berlin: Logos Verlag, 2015).

${ }^{3}$ Diesner, Die Allgemeine Systemtheorie bei Ludwig von Bertalanffy. Eine Begründung interdisziplinärer Wissenschaftspraxis.

${ }^{4}$ Eduard Müller, Cash-crop with animal production systems: coffee, sugarcane with dualpurpose cattle (Turrialba: CATIE, 1982).

${ }^{5}$ Ross D. Arnold and Jon P. Wade, "A Definition of Systems Thinking: A Systems Approach," Procedia Computer Science 44, (2015): 669-678. 


\section{Holistic Approaches}

In order to advance with holistic approaches, we need to transcend the individual disciplines. Transdisciplinarity gives us the possibility for developing holistic approaches and proves that the true interaction of different disciplines can have a result that is greater than the sum of the different disciplines. It therefore transcends each discipline and requires viewing our subject matter from different perspectives and even different time frames. Nicolescu describes it as a unity of knowledge beyond disciplines. ${ }^{6}$ The caveat is that in order to be successful in working with transdisciplinarity, participating individuals need to understand the different disciplines and have the skills to promote and mediate dialogue to assure full integration across the board.

This is where we hit one of the most important obstacles in modern education. Even if a university decides to take on the task of incorporating holism, getting adequate teachers is an enormous challenge, since most of them have been educated under reductionism. Many academics that are interested in holistic approaches are viewed by their peers as "light" or superficial while holistic academic development is also hampered by the ranking methods used in most of the world. Transdisciplinary journals are scarce and are not considered to be among the most prestigious, thus the academic points given to holistic research are not an incentive. Holistic approaches often require the integration of intangible aspects, difficult to process with statistics and subjective analysis is not considered scientific by many. The knowledge dialogue, well known in Latin America as diálogo de saberes - the conversation between conventional science and local or indigenous knowledge-is a fundamental part of transdisciplinarity but has been historically regarded as non-scientific and it is not until recent years that it is gaining importance, due to the difficulty of solving complex problems at the local level.

\section{Higher Education in Costa Rica: University FOR INTERNATIONAL COOPERATION's (UCI) EXPERIENCE}

In Costa Rica, higher education is highly regulated by the Ministry of Education, resulting in antiquated rigid rules that act as heavy anchors to the evolution of education. Most people making decisions about universities,

\footnotetext{
${ }^{6} \mathrm{Nicolescu}$, Manifesto of Transdisciplinarity.
} 
programs, curricula and even course contents are not academics and have been bureaucrats for decades. Professional activity is regulated by outdated laws that do not allow the evolution of new professions.

At UCI, we have had degree programs not approved by the ministry because the graduates did not have a professional association under which to affiliate themselves. One good example is the Bachelor's degree in Protected Area Management, a pioneer program launched two decades ago. The ministry at first did not approve the program because the professional association for biologists said it was administration and not biology, while the professional association of business said it was too biologic and not administrative. It took years of persuasion to finally get the program approved.

In order to reach out to students in the most remote places with highquality programs, at UCI we started with distance learning using the internet in the mid-1990s but it took a decade convincing the ministry that learning in a non-face-to-face environment was possible. One of the major questions was how do you assure that the person on the other side is the person who is studying and not someone else helping them out? Other questions dealt with the lack of human contact which is vital to learning or the need for group work that could not be satisfied through communication technology. Today, many of these issues have slowly faded away but there is still a long road ahead. For example, we are still required to have a hard copy of all literature used in our online programs in a physical library (actually a book museum), even if a student will never step into our building. In Costa Rica and most Latin American countries, in order for teachers to be approved and officially allowed to teach in a degree program, they have to get their degrees recognized by the ministry, a process which can take months or even years. Having international teachers from all over the world is a plus that the majority of face-to-face programs cannot afford. After more than two decades of experience, we know that the learning experience in a vast array of fields can be greater through e-learning. The possibility of having students from ten or more countries interacting, doing group work, comparing realities, bringing in cultural aspects and real-time discussions of different national realities has proven to considerably enrich the learning process.

When regulating and managing online learning, the government and many universities still focus on technology, which is also a misguided practice and is the reason why some online programs are unsuccessful. Technology definitely helps but above all, learning methodologies—where 
we have an ever-growing diversity to choose from-have to be used intelligently. Today, a great learning experience can be brought to a group of students in real time using applications like WhatsApp. In Costa Rica, all academic programs have to be authorized by the Ministry of Education; a process which may take well over a year or two. For the evaluation of these programs, authorities require, for example, that all courses be uploaded to the virtual campus before submitting the program for approval. This is clear proof that these authorities have no clue about education. By the time the program is approved, these course contents will be outdated and even the software version will probably be obsolete. The fact that a curriculum, the course contents, bibliography and even the teachers have to be approved by a central authority before being offered to students will soon make higher education obsolete and internationally based programs will wipe out local universities.

A problem that many universities in the region still face is the focus on knowledge. Students frequently continue to be exposed to hours of effort to acquire information and knowledge. A teacher, many times highly considered for being owner of knowledge, evaluates his or her students by how much of that knowledge is retained. Grading is done through exams based on mere repetition of memorized stuff. Today, information and knowledge are being produced at rates thousand times greater than the past, making it impossible for any human being to be up to date. Google and other search engines can give us, within seconds, all the information that we require. Soon AI will make the processing of this information more effective than the human brain, which cannot do data mining and analytics using huge databases in milliseconds. With change happening so fast, it is more relevant for students to be able to find the necessary information and knowledge, than try storing it in their brain. Acquired knowledge can become obsolete before it can be used. Finding a balance on what is the minimum knowledge a student needs to be able to correctly sort out the necessary information in a self-learning or flipped classroom process is not simple and will vary from individual to individual. Nevertheless, in the near future, knowledge acquisition will probably happen mostly outside the classroom.

The concept of skill-based learning was introduced into universities by the business sector that wanted professionals that could actually get things done. We can define skills as "the ability to do something that comes from training, experience, or practice" ${ }^{7}$ or "the learned ability to bring about

\footnotetext{
7 "Merriam-Webster Dictionary Online," Merriam-Webster Dictionary, Accessed August 22, 2017, https://www.merriam-webster.com.
} 
predetermined results with maximum certainty, often with the minimum outlay of time or energy or both." We have seen a shift over the last years in the importance of 'hard skills'- "the capabilities required for specific occupations usually related to professional knowledge, tools, or techniques that allow us to work within our profession"-toward a greater importance of 'soft skills' (also called 'people skills')—“the complete collection of our social, communication, and self-management behaviors and are vital for professional success." ${ }^{9}$ Business usually prefers professionals with excellent soft skills who can learn what they need to know on the job. We must be aware that developing soft skills can be more difficult than learning the hard ones.

The concept of competence or competency has added another level of complexity. ${ }^{10}$ In many places, competence is limited to skills and knowledge. In most of Latin America it reflects the concept of "good performance in diverse, authentic contexts based on integration and activation of knowledge, rules and standards, techniques, procedures, abilities and skills, attitudes and values (emphasis added)." "At UCI we are trying to get another layer on the top, passion, which we believe will give professionals the most value in designing their careers and life, by providing powerful energy to pursue even the most difficult challenges, which will be very necessary in the years ahead.

\section{Education into the Future}

It is already clear that higher education will change significantly in the near future. Many emerging learning platforms such as Singularity University, Udemy, Udacity, EdX, Coursera and many more are competing with traditional universities by offering flexible online learning possibilities that are allowing students to individually design their careers according to their specific demands. This represents one big challenge to many universities that will have to adapt or perish. On the other hand, global and climate changes are creating new challenges that are not being currently addressed

\footnotetext{
${ }^{8}$ Barbara Knapp, Skill in Sport: The attainment of proficiency (London: Routledge \& Kegan Paul, 1963), 4.

${ }^{9}$ Eduard Müller et al., "Capacity Development," In Protected Area Governance and Management, eds. Graeme Worboys et al. (Canberra: ANU Press, 2015), 251-291.

${ }^{10}$ For more on competence, see Müller et al., "Capacity Development."

${ }^{11}$ Aurelio V. Sanchez and Manuel P. Ruiz, eds. Competence-based learning (Bilbao: University of Deusto, 2008), 29.
} 
with effective holistic approaches. Educating people to respond to these challenges opens new opportunities.

\section{Challenge 1: Disruption}

Throughout the world, a rapid shift has started on how we learn. We experienced the birth of the MOOCs at the start of this decade and now see a rapid migration to micro-courses, co-creation platforms, design thinking and many others, which are greatly potentiated by emerging and exponential technology. As Ray Kurzweil, futurist and co-founder and chancellor of Singularity University, states: "We're in an era where we can make ourselves smarter with machines, not just with access to information at our fingertips through mobile devices, but we're on the cusp of being able to reprogram our outdated human software DNA." 12 This will probably be the definite challenge universities will be facing in the next few years and will probably define which ones survive. According to Ahmad Hasnah of Hamad bin Khalifa University "Students in the future will take their education from many different providers, and the problem in higher education is that we work in institutions that are perfectly adapted for environments that no longer exist." 13

As a report from the Center for American Progress states, "This emerging disruptive innovation also presents an opportunity to rethink many of the age-old assumptions about higher education-its processes, where it happens, and what its goals are-and to use the disruptive start-up organizations to create institutions that operate very differently and more appropriately to address the country's challenges." 14 This report gives several recommendations to policymakers:

1. "eliminate barriers that block disruptive innovations and partner with the innovators to provide better educational opportunities";

2. "remove barriers that judge institutions based on their inputs such as seat time, credit hours, and student-faculty ratios";

12 “Singularity University," Singularity University, August 9, 2016, https://su.org/about/ press-room/press-releases/singularity-university-addresses-the-worlds-greatest-challengesat-su-global-summit/.

${ }^{13}$ Paul Rigg, "University World News," October 31, 2014, http://www.universityworldnews.com/article.php? story $=20141030125107100$.

${ }^{14}$ Clayton M. Christensen et al., Disrupting College, How Disruptive Innovation Can Deliver Quality and Affordability to Postsecondary Education (Washington, D.C.: Center for American Progress, 2011), 4. 
3. "not focus on degree attainment as the sole measure of success";

4. "fund higher education with the aim of increasing quality and decreasing cost";

5. "recognize the continued importance of research institutions." 15

We live in a rapidly changing world where most of the in-demand occupations today did not exist five or ten years ago, where children born today will never learn how to drive a car or may not even own one, where the largest companies such as Uber, Expedia, Trip Advisor or Airbnb do not have fixed assets. AI and robotics have gone beyond manufacturing lanes. It is easy to understand why these will displace jobs at call centers (AI can already predict urgency of the call before it is answered), supermarkets (Tally-fully autonomous system for auditing shelves for out-of-stock items, low stock items, misplaced items and pricing errors), construction (brick-laying robots-Haradian X, 3D printed buildings), remote 3D printing of spare parts, medicine (IBM's Watson image interpretation and database analytics for treatment determination), law (data analytics, jurisprudence, legal document reviews). According to the World Economic Forum, by 2020 , over 7 million jobs will have been lost due to disruptive labor market changes while 2 million new jobs will have been created, mainly in data analysis, commercializing, energy and media, entertainment and information. ${ }^{16}$

\section{Challenge 2: Education for the Future, Beyond Sustainable Development}

As an end result of all the aspects discussed above, higher education is facing one or more turning points and will have to adapt rather rapidly in order to survive, but even if it can adapt to the above challenges, will it be enough to help save humanity? What are the most important problems humanity is facing today? How can we truly address them? Will the technological advances be sufficient to revert planetary degradation? What else will higher education have to include to recover or maintain conditions for human livelihoods? These key questions highlight the importance of a new paradigm for development.

\footnotetext{
${ }^{15}$ Clayton M. Christensen et al., Disrupting College, 4-5.

${ }^{16}$ World Economic Forum, The Future of Jobs: Employment, Skills and Workforce Strategy for the Fourth Industrial Revolution (Geneva: World Economic Forum, 2016), http:// www3.weforum.org/docs/WEF_Future_of_Jobs.pdf.
} 
We have promoted degenerative development with massive resource extraction. If we look at the relation between the ecological footprint and biocapacity, we have clearly surpassed Earth's capacity to satisfy our current consumption; today we require the equivalent of 1.7 planets to provide the resources used and to absorb the waste produced. What we consume in one year takes Earth 18 months to regenerate. ${ }^{17}$ In this destructive pathway, it seems that humans have forgotten that the natural world is what makes life possible, including ours. We need nature, nature does not need us!

At UCI we are convinced that higher education must go beyond the technological developments discussed under challenge 1 . We need to clearly identify the main factors responsible for the collapse of our planet and of civilization as a whole. These need to be addressed with the highest priority, expertise and resources. At the same time, these challenges represent unlimited opportunities for new jobs that will provide great satisfaction in making a better world for all people. We cannot solve the mess we are in by using the same mindset and methods that have gotten us here. We need to urgently measure development with indicators other than those that have been used for decades. Using Gross Internal Product to measure progress is perverse. Measuring success with revenue that does not contemplate the true cost of the resources consumed or destroyed is immoral. Exploitation of fellow human beings to bring products at ridiculous prices for those who can consume should not be tolerated. And above all, we must remember that we have not inherited the planet, we are borrowing it from our children, grandchildren and future generations.

To be able to answer the above key questions and define priorities for education and capacity development we use the planetary boundaries concept, which can be easily understood by most groups of people.

\section{Planetary Boundaries}

The planetary boundaries approach was developed in an attempt to define the 'safe operating space for humanity'-meaning the conditions required for humans to develop and thrive, based on the biophysical processes that regulate the stability of Earth's system. ${ }^{18}$ We have already crossed four of

\footnotetext{
17 “Global Footprint Network," Global Footprint Network, 2017, http://www.footprintnetwork.org/.

${ }^{18}$ Will Steffen et al., "Planetary boundaries: Guiding human development on a changing planet," Science 347, no. 6223 (2015): 1259855.
} 
nine planetary boundaries and these are the loss of biosphere integrity (biodiversity loss), land system change, the biogeochemical flow and climate change. Of these, climate change and biosphere integrity have each the potential to drive the Earth system into a new state, which will not allow our civilization to thrive.

\section{LOSS OF BIOSPHERE INTEGRITY}

The importance of biodiversity loss has been recognized for a long time. In 2002, countries set a goal that by 2010 the loss would be halted. This did not happen so that year in Nagoya, Japan, at the Convention of Biological Diversity COP10, the ball was kicked forward for another decade and the 2011-2020 Strategic Plan to halt biodiversity loss was agreed upon. The plan consisted of 20 very clear targets (Aichi targets) which countries agreed to achieve. With less than three years to go, we are not even close to achieving this target. Biodiversity loss has escalated to unprecedented levels. Current extinction rates are about 1000 times above the background rates ${ }^{19}$ and as mentioned earlier, we are now in the sixth planetary extinction. ${ }^{20}$ One problem that is ignored by many is that ecosystems can only tolerate a certain loss of biodiversity before losing their capacity for supporting life on Earth, including humans and though we are not clear where these limits are, we are already seeing ecosystem collapses at a scale that has never been witnessed by humans before. Ocean warming, acidification and pollution are changing and killing the largest ecosystem on the planet. On land, biological diversity has fallen below the proposed planetary boundary in about $60 \%$ of the land surface of the planet where more than $70 \%$ of humans live. ${ }^{21}$ Habitats continue to be degraded and by the time the 2020 date is reached we will have lost two-thirds of vertebrate populations. ${ }^{22}$ According to the WWF,

\footnotetext{
${ }^{19}$ Stuart Pimm et al., "The biodiversity of species and their rates of extinction, distribution, and protection," Science 344, (2014): 1246752.

${ }^{20}$ Gerardo Ceballos et al., "Accelerated modern human-induced species losses: Entering the sixth mass extinction," Science Advances 1, no. 5 (2015): el400253.

${ }^{21}$ Tim Newbold et al., "Has land use pushed terrestrial biodiversity beyond the planetary boundary? A Global assessment," Science 353, no. 6296 (2016): 288-291.

${ }^{22}$ WWF, Living Planet Report 2016. Risk and resilience in a new era (Gland, Switzerland: WWF International, 2016).
} 
To maintain nature in all of its many forms and functions and to create an equitable home for people on a finite planet, a basic understanding must inform development strategies, economic models, business models and lifestyle choices: we have only one planet and its natural capital is limited. A shared understanding of the link between humanity and nature could induce a profound change that will allow all life to thrive in the Anthropocene. ${ }^{23}$

Pollinators are declining rapidly affecting agricultural and natural systems, while pests and invasive species are causing unprecedented harm to food security. Reports keep piling up on the graveness of the situation and the dire implications for humans without triggering the action that is needed. We are still putting economic gain above future life.

\section{Biogeochemical Flows}

Excessive use of fertilizers (nitrogen and phosphorus) has led to the crossing of another planetary boundary. ${ }^{24}$ In spite of the lack of media coverage, disturbances to the nitrogen cycle are greater than those of the carbon cycle. ${ }^{25}$ Between $30 \%$ and $80 \%$ of anthropogenic nitrogen used in agriculture leaks into the environment harming soil, ecosystems and human health while contributing to changes in the global climate system. ${ }^{26}$ Nitrous oxide is the third most important greenhouse gas $^{27}$ with a global warming potential almost 300 times that of $\mathrm{CO}_{2} \cdot{ }^{28}$ Over the last decades, academic institutions and the petrochemical industry have misled the world to believe that we need 'agricultural packages' consisting of agro-

${ }^{23}$ WWF, Living Planet Report 2016.

${ }^{24}$ Steffen et al., "Planetary boundaries: Guiding human development on a changing planet."

${ }^{25}$ Scott Fields, "Global Nitrogen: Cycling out of Control," Environmental Health Perspectives 112, no. 10 (2004): A556-A563.

${ }^{26}$ Eric A. Davidson, "The contribution of manure and fertilizer nitrogen to atmospheric nitrous oxide since 1860," Nature Geoscience 2, (2009): 659-662; Daniel J. Sobota et al., "Cost of reactive nitrogen release from human activities to the environment in the United States," Environmental Research Letters 10, no. 2 (2015): 025006; Jules Pretty, "Agroecological Approaches to Agricultural Development," November 2006, https:// openknowledge.worldbank.org/handle/10986/9044.

${ }^{27}$ IPCC, Climate Change 2014: Synthesis Report (Geneva: IPCC, 2014).

28 "Understanding Global Warming Potentials," EPA, August 9, 2016, https://www.epa. gov/ghgemissions/understanding-global-warming-potentials. 
chemicals, irrigation, high yielding varieties, genetically modified organism and mechanization to feed the world, while international reports show the contrary. The use of pesticides is backed by similar false affirmations; a recent report from the United Nations states: "There continues to be a general lack of awareness of the dangers posed by certain pesticides, a condition exacerbated by industry efforts to downplay the harm being done as well as complacent Governments that often make misleading assertions that existing legislation and regulatory frameworks provide sufficient protection." 29

\section{Land System Change}

Humans have altered landscapes for millennia. Throughout history, these changes have had local consequences; some of them have caused the rise and fall of previous civilizations such as the case of the Maya's in Central America. Currently, the extent of degradation is having global effects. Land degradation increases greenhouse gases and also the risks associated with climate change. It is also a major driver for biodiversity loss. Humans have already degraded over 1.5 billion hectares of land, corresponding to 550 million in Asia Pacific, followed by Africa with 500 million and Latin America with 300 million. ${ }^{30}$

Soil degradation is mainly due to wrong agricultural practices that are still being taught at universities and promoted through ministries of agriculture. Today, corporate agriculture has surpassed subsistence agriculture in causing the degradation. Agricultural expansion has also increased significantly the demand for water, accounting for $70 \%$ of the water withdrawals for irrigation at global level, reaching more than $90 \%$ in least developed countries. ${ }^{31}$ There is an urgent need to regenerate degraded land, establishing functional landscapes that allow ecosystems to keep on providing essential services vital for life support. Though complete

${ }^{29}$ United Nations, Report of the Special Rapporteur on the right to food (New York: United Nations, 2017), 22.

30 “Tackling Land Degradation and Desertification," IFAD, 2002, https://www.ifad.org/ topic/resource/tags/desertification/2085419.

${ }^{31}$ UNESCO, The United Nations World Water Development Report 2016 (Perugia: UNESCO, 2016), http://unesdoc.unesco.org/images/0024/002440/24404le.pdf. 
regeneration of ecosystems will require decades or centuries, and might never be possible, it is the best bet we have in fighting our largest challenges today.

\section{Climate Change}

Climate change, while not yet as exacerbated as biodiversity loss, is a very important planetary boundary that has already been crossed and is accelerating at unprecedented rates. We have reached record-breaking temperatures throughout the last two decades. A great paradox lies in the fact that the last time humans could breathe in a normal atmosphere was during the 2015 Paris meetings, when the planet surpassed the $400 \mathrm{ppm}$ milestone permanently, ${ }^{32}$ the highest value in millions of years. Scientists are affirming that critical tipping points have been crossed or are in the verge thereof; global warming is close to becoming irreversible. Climate change information clearly indicates the urgency for action to save our current civilization. What was once debatable doom and gloom information is now underpinned by the most rigorous scientific evidence. In February 2016 global temperature reached $1.35^{\circ} \mathrm{C}^{33}$ which is very close to the $1.5^{\circ} \mathrm{C}$ mark that is supposed to be reached in 83 years, a clear reason for immediate action.

Climate change not only causes direct changes in most of Earth's systems but also fosters other anthropogenic processes ending with rapid deterioration of basic conditions for life, seriously compromising land, freshwater and oceanic ecosystems. Natural and productive ecosystems are becoming less resilient. Countries are losing more and more crops, and food shortages are affecting millions of people, especially the poor. Water supply is decreasing in many regions at alarming rates. We urgently need new approaches, policies and actions to create 'counter-tipping points' to balance human development with the natural world. Climate change adaptation and mitigation require that the root causes of global change be addressed and that we move from knowing to doing.

\footnotetext{
${ }^{32}$ Brian Kahn, "Earth's $\mathrm{CO}_{2}$ Passes the 400 PPM Threshold - Maybe Permanently," Scientific American, September 27, 2016, https://www.scientificamerican.com/article/ earth-s-co2-passes-the-400-ppm-threshold-maybe-permanently/.

33 "GLOBAL Land-Ocean Temperature Index in 0.01 degrees Celsius base period: 1951-1980," NASA GISS, accessed January 21, 2017, https://data.giss.nasa.gov/gistemp/tabledata_v3/GLB.Ts+dSST.txt.
} 


\section{Why the Boundaries Have Been Exceeded: A Brief ANALYSIS}

It is clear that Earth's capacity to maintain life as we know it is seriously compromised. "We stand at a critical moment in Earth's history, a time when humanity must choose its future." ${ }^{34}$ Global change is with us, its consequences also. From more simple problems as vanishing pollinators, plummeting fish stocks and plastic pollution to complex issues such as climate change and poverty, we have managed to push our planet into a different future. Currently, as mentioned above, we are not able to maintain our life supporting planetary services, putting our civilization, together with many other life forms, at risk of extinction.

Economic development has been the primary focus of development over the last century and probably the single most important cause of our current disastrous situation. The linear economic model imposed on us with the promise that ever-increasing economic growth and the globalization of markets would trickle down benefits to everyone has left hundreds of millions of people without access to the so-called development. John Fullerton states that "our latest scientific understanding tells us that, notwithstanding its many achievements, today's form of capitalism rests upon outdated reductionist thinking that is fundamentally at odds with both the finite boundaries of the biosphere and the laws of systemic health in an interconnected world." ${ }^{35}$

Our social structures throughout many countries are broken. Sumptuous consumption and apparent ignorance of the consequences of our daily actions on our future-excess food and overweight societies that coexist with simultaneous starvation - the reluctance to giving up individual rights in favor of community ones or even planetary survival and many other factors prove this. We have developed into egotistic people who think of our world as if we own it and have the right to use and abuse it in favor of our comfort. Much of the initial trend was set in the United States, making them the largest contributor to global change until a decade ago. The problem is that this was exported to most of the world, promoted by international policies, including those of multilateral finan-

\footnotetext{
34 "The Earth Charter," Earth Charter Initiative, last updated 2016, http://earthcharter. org/discover/the-earth-charter/.

${ }^{35}$ Fullerton, Regenerative Capitalism: How universal principles and patterns will shape our new economy (Greenwich: Capital Institute, 2015), 34.
} 
cial institutions. Today, our society puts individual rights above collective ones and does not understand the meaning of solidarity.

Initial blame for this consumerism falls upon the automobile, one of the worst decisions humanity has made. David Blanks states

As a powerful symbol of modernity, the automobile represented individual freedom, mobility, and independence. The car also linked the profound economic changes (especially the rise of big business) to the pursuit of personal happiness through consumption. Increasingly, Americans defined a happy life by one that offered personal and immediate gratification, even if this meant rising debt and a loss of local community. ${ }^{36}$

Propaganda (dissemination of information-facts, arguments, rumors, half-truths or lies-to influence public opinion $)^{37}$ invented by Edward Bernays in the late 1920s was the basis to promote consumerism-a wellknown example being linking women's equality to men through cigarette smoking. ${ }^{38}$

Culture is what [still] makes us different from one another (e.g. Chinese, Japanese, German or Costa Rican). It is what woke the interest in tourism, even before nature was appreciated. I consider culture to be the 'glue' of our societies. Nevertheless, culture is being whipped out at speeds even faster than nature. Mass media, social networks, fashion, stuff, all have contributed to creating uniformity throughout the planet. Family structures, community organization and care, solidarity and many other characteristics that were unique to countries or regions are vanishing, being substituted by brand names and the need to accumulate things that are designed and built with programmed obsolescence to increase sales through repeated purchasing. When people lose their culture or consider it less than other cultures, they lose self-esteem and start imitating other cultures to try to fit in.

Politics have gone wrong in many countries, even those with democratic tradition. Short-term thinking, benefits for just a few, corporations

\footnotetext{
${ }^{36}$ David Blank, "Rise of the Automobile," accessed August 25, 2017, http://teachinghistory.org/history-content/beyond-the-textbook/24073.

${ }^{37}$ Bruce L. Smith, "Propaganda," last updated April 18, 2017, https://www.britannica. com/topic/propaganda.

${ }^{38}$ Wendy Christensen, "Torches of Freedom: Women and Smoking Propaganda," February 27, 2012, https://thesocietypages.org/socimages/2012/02/27/torches-of-freedom-womenand-smoking-propaganda/.
} 
controlling politicians, corruption, and many other wrongdoings are now common ground. What is called corruption in some countries is called lobbying in others-and is legal. However we look at it, buying a politician's favor is not correct, it is not moral. Youth is disappointed and does not want to get involved in politics. Democracies have turned into election events with almost no civil participation in between these.

Spirituality-detached from religious beliefs-has been left behind. The scientific approach, as we explained earlier, separated humans from nature and pushed our educational process toward physics. I consider spirituality to be the only true pathway that will allow us a paradigm shift of the magnitude and urgency required. A person's heart must be touched. We need deep consciousness of what we are doing, individually and collectively. Recognizing individual responsibility is essential and the starting point. Each and every one of us must begin to change. Individual responsibility has to be then collectivized to be able to reach the scale we need. Higher education needs to support this mindset if we are to effectively adapt to a world where the technologies of fourth industrial revolution (4IR) combine with the impacts of climate change.

Another constraint of modern science and its education is that it must be fact based; any spiritual or intangible component is traditionally not contemplated. I personally feel that without the spiritual component, advancement in solving our complex problems of today will be slow. When discussing this subject with university leaders, especially those from developed countries, I always get questioned on how to measure spirituality, and since I cannot measure it, why teach it? There are no current methods to effectively teach spirituality, but it can and must definitely be promoted among our students. Open discussions, mindfulness, living nature, experiencing real-life situations in the poorest or at-risk populations, getting out of our bubbles, seeing the world and understanding the true meaning of life will surely change the mindsets of the majority of students.

However, we have not been effective at educating for sustainable development. As mentioned before, complex issues cannot be addressed through the traditional disciplinary approaches. Over the last three decades, we have been discussing sustainable development, holding hundreds of conferences all over the world, first to agree on a definition and then on how to achieve it, with hundreds of beautiful booklets and reports printed. Yet, we are not even close to achieving or at least curbing rate of global destruction. In the early definitions, sustainable development was about leaving future generations similar conditions to the ones we inherited. 
Now, it is about all present human beings, irrelevant of age, class or race, being able to make the change that will allow our civilization as a whole to have a future. By now, it will be a different future, but the more we wait to take action, the more people will be vulnerable, the more people will suffer and the whole foundation for our current civilization will be undermined.

\section{Regenerative Development}

In order to move forward and have livable conditions in the future, we must immediately stop degenerative development. A clear example is the environmental impact assessment that gives a company, government or any project the possibility to get approved as long as it minimizes environmental and social impacts. Under the conditions the planet is today, this is immoral, any project must have positive impacts in nature and society; economy cannot be placed on top of life-sustaining ecosystems and human well-being.

To revert our self-destructive pathway, we need to modify what we have been doing so far, moving to holistic approaches that optimize Earth's biocapacity (the planet's biologically productive land areas) while keeping our footprint within the planetary boundaries. This can only be achieved through true transdisciplinarity. Academic programs must also shift to intensive knowledge and data use incorporating local knowledge-adapting to climate change is very local, there are no recipes. Current dynamism also will require programs to be more prospective, looking into the future. Retrospective management based on yearly plans and end-of-year achievements will not suffice. They must adopt prospective or creative management which uses climate change and socio-economic future scenarios to deal with complexity and uncertainty in the development of plans and policies for climate change. ${ }^{39}$

Regenerative development will provide for the creation of thousands of new jobs, especially but not exclusively in developing countries. New professions will arise as new challenges appear. Great opportunities for knowledge and experience exchange will lead to innovative partnerships for co-creation of methods and processes.

\footnotetext{
39 "Marieke Veeger," CCAFS-CGAIR, August 22, 2017, https://ccafs.cgiar.org/about/ people/marieke-veeger\#.WZyCaSiGM2w.
} 
Regenerative development starts with a profound reform in our way of doing things, by holistically integrating six fundamental pillars, including

1. regeneration of functional landscapes, where we produce and conserve in a defined gradient of uses, maximizing biodiversity and ecosystem function to guarantee the provision of the basic ecosystem services to sustain life on Earth, including ours;

2. social strengthening by community organization, empowerment and development to allow local communities to recognize and reverse their negative behavioral patterns and enhance the positive ones to allow them to cope with adaptation to a changing planet, including climate change, and reduce sumptuous consumption patterns;

3. a new paradigm for economic development where people matter more than markets and money, measured according to the wellbeing of humans and all life forms, based on the circular principles of nature, where 'waste' is the input to another part of the system, nothing is disposable;

4. conservation and valuation of living culture which is the necessary bond for community life, where local knowledge, values and traditions are shared within family, friends and the community as a whole, giving meaning to these terms, where self-esteem is recovered and enhanced, allowing community proudness to facilitate collective action and the true achievement of a harmonious relation with all;

5. rethinking and redesigning current political structures so they reflect true participatory democracy and inclusiveness, without the influence of money and power and especially fostering long-term vision and actions that seek increased livelihoods and happiness and not only gross income;

6. fostering deep spiritual and value structures based on ethics, transparency and global well-being to allow humanity to live in peace with itself and planet Earth.

In practice, implementation of regenerative development requires a close participation of different experts from a diverse set of disciplines and at least one leader that has the competences to lead this team to work in a transdisciplinary manner. Basing the approach on a specific territory is key. The six main aspects to be contemplated can be looked upon as blankets that are laid one over the other. Our focus cannot be the individual blanket-it must look at the vertical interaction between them. Many different 
methods can be integrated in the educational process. We have been most successful by applying the competence framework mentioned earlier.

All sectors of society have to act promptly to save life on our planet and reestablish a balance that will allow our civilization to thrive for centuries to come. The problem is that few actually know how to do this. In order to offer an immediate solution, we need to move to innovative educational programs to satisfy the need of highly qualified professionals to effectively and efficiently promote a new paradigm for development. The highly developed competences in managing projects together with the unique competences on regenerative development offer private and public sectors the manpower to address the urgent action that is needed to reverse the current situation and allow for future prosperity and human happiness.

Regenerative development is rapidly gaining global momentum and again UCI is a pioneer in this holistic approach. Graduates will have a higher ability to go far beyond other professionals, resulting in effective positive change within their organizations, by showing strong differentiation with positive impacts in the well-being of society and the environment, while increasing the economic benefits. Investing in this globally unique master's program will open numerous possibilities both for the professional as well as for their organizations, through the enhanced environmental and social responsibility, sensitivity and consciousness. The international exposure and experience bring along a whole other set of extraordinary competences.

Education for regenerative development faces many challenges. Developing competences for holistic approaches will be difficult. A good starting place is to un-learn many of the things that were taught to us. We need to develop a much stronger critical analysis of what is considered good for development. We also need to reevaluate how we do science and manage knowledge. The last sentence of the Earth Charter states: "Let ours be a time remembered for the awakening of a new reverence for life, the firm resolve to achieve sustainability, the quickening of the struggle for justice and peace, and the joyful celebration of life." ${ }^{40}$ It is likely that the 4IR will enable an awakening of many kinds, one in which we reimagine our humanity. The ideas of regenerative development should be integrated into higher education curriculum and administration in order to ensure that the learning supports a sustainable future.

${ }^{40}$ Earth Charter Initiative, "The Earth Charter." 


\section{BIBLIOGRAPHY}

Arnold, Ross D. and Jon P. Wade. "A Definition of Systems Thinking: A Systems Approach." Procedia Computer Science 44, (2015): 669-678.

Baker, Monya. "1,500 scientists lift the lid on reproducibility." Nature 533, no. 7604 (2016): 452-454.

Blank, David. "Rise of the Automobile." Accessed August 25, 2017. http:// teachinghistory.org/history-content/beyond-the-textbook/24073.

CCAFS-CGAIR. "Marieke Veeger." August 22, 2017. https://ccafs.cgiar.org/ about/people/marieke-veeger\#.WZyCaSiGM2w.

Ceballos, Gerardo, Paul R. Ehrlich, Anthony D. Barnosky, Andres Garcia, Robert M. Pringle, and Todd M. Palmer. "Accelerated modern human-induced species losses: Entering the sixth mass extinction." Science Advances 1, no. 5 (2015): el400253.

Christensen, Clayton M., Michael B. Horn, Louis Caldera, and Louis Soares. Disrupting College, How Disruptive Innovation Can Deliver Quality and Affordability to Postsecondary Education. Washington, D.C.: Center for American Progress, 2011.

Christensen, Wendy. "Torches of Freedom: Women and Smoking Propaganda." February 27, 2012. https://thesocietypages.org/socimages/2012/02/27/ torches-of-freedom-women-and-smoking-propaganda/.

Davidson, Eric A. "The contribution of manure and fertilizer nitrogen to atmospheric nitrous oxide since 1860." Nature Geoscience 2, (2009): 659-662.

Diesner, Thomas. Die Allgemeine Systemtheorie bei Ludwig von Bertalanffy. Eine Begründung interdisziplinärer Wissenschaftspraxis. Berlin: Logos Verlag, 2015.

Earth Charter Initiative. "The Earth Charter." Last updated 2016. http:// earthcharter.org/discover/the-earth-charter/.

EPA. "Understanding Global Warming Potentials." August 9, 2016. https:// www.epa.gov/ghgemissions/understanding-global-warming-potentials.

Fields, Scott. "Global Nitrogen: Cycling out of Control." Environmental Health Perspectives 112, no. 10 (2004): A556-A563.

Fullerton, John. Regenerative Capitalism, How universal principles and patterns will shape our new economy. Greenwich: Capital Institute, 2015.

Global Footprint Network. "Global Footprint Network." 2017. http://www. footprintnetwork.org/.

IFAD. "Tackling Land Degradation and Desertification." 2002. https://www. ifad.org/topic/resource/tags/desertification/2085419.

Ioannidis, John P. A. "Why Most Published Research Findings are False." PLos Med 2, no. 8 (2005): el24.

-. "Why Science Is Not Necessarily Self-Correcting." Perspectives on Psychological Science Self-Correcting 7, no. 6 (2012): 645-654.

IPCC. Climate Change 2014: Synthesis Report. Geneva: IPCC, 2014. 
Jandric, Petar. "From Anthropocentric Humanism to Critical Posthumanism in Digital Education." In Learning in the Age of Digital Reason, 195-210. Rottendam, Sense Publishers, 2017.

Kahn, Brian. "Earth's $\mathrm{CO}_{2}$ Passes the 400 PPM Threshold - Maybe Permanently." Scientific American, September 27, 2016. https://www.scientificamerican.com/ article/earth-s-co2-passes-the-400-ppm-threshold-maybe-permanently/.

Knapp, Barbara. Skill in Sport: The attainment of proficiency. London: Routledge \& Kegan Paul, 1963.

Macleod, Malcom, Susan Michie, Ian Roberts, Ulrich Dirnagl, Iain Chalmers, John P.A. Ioannidis, Rustam Al-Shahi Salman et al. "Biomedical research: increasing value, reducing waste." The Lancet 383, no. 9912 (2014): 101-104.

Merriam-Webster Dictionary. "Merriam-Webster Dictionary Online." Accessed August 22, 2017. https://www.merriam-webster.com.

Müller, Eduard. Cash-crop with animal production systems: coffee, sugarcane with dual-purpose cattle. Turrialba: CATIE, 1982.

Müller, Eduard, Michael Appleton, Glenn Ricci, Allan Valverde, and David Reynolds. "Capacity Development." In Protected Area Governance and Management. Edited by Graeme Worboys, Michael Lockwood, Asish Kothari, Sue Feary, and Ian Pulsford, 251-291. Canberra: The Australian National University, 2015.

NASA GISS. "GLOBAL Land-Ocean Temperature Index in 0.01 degrees Celsius base period: 1951-1980." Accessed January 21, 2017. https://data.giss.nasa. gov/gistemp/tabledata_v3/GLB.Ts+dSST.txt.

Newbold, Tim, Lawrence N. Hudson, Andrew P. Arnell, Sara Contu, Adriana De Palma, Simon Ferrier, Samantha L. L. Hill et al. "Has land use pushed terrestrial biodiversity beyond the planetary boundary? A Global assessment." Science 353, no. 6296 (2016): 288-291.

Nicolescu, Basarab. Manifesto of Transdisciplinarity. Albany: State University of New York Press, 2002.

- "Methodology of transdisciplinarity - levels of reality, logic of the included middle and complexity." Transdisciplinary Journal of Engineering \& Science 1, no. 1 (2010): 19-38.

Pimm, Stuart, C. N. Jenkins, R. Abell, T. M. Brooks, J. L. Gittleman, L. N. Joppa, P. H. Raven, C. M. Roberts, and J. O. Sexton. "The biodiversity of species and their rates of extinction, distribution, and protection." Science 344, (2014): 1246752.

Pretty, Jules. “Agroecological Approaches to Agricultural Development.” November 2006. https://openknowledge.worldbank.org/handle/10986/9044.

Raworth, Kate. "Old economics is based on false 'laws of physics' - new economics can save us.” April 6, 2017. https://www.theguardian.com/global-developmentprofessionals-network/2017/apr/06/kate-raworth-doughnut-economics-neweconomics. 
Rigg, Paul. "University World News." October 31, 2014. http://www.universityworldnews.com/article.php?story=20141030125107100.

Sanchez, Aurelio V. and Manuel P. Ruiz, eds. Competence-based learning. Bilbao: University of Deusto, 2008.

Savenije, Davide. "Education Drive." July 24, 2013. http://www.educationdive. $\mathrm{com} /$ news/4-ways-universities-can-survive-extinction/148644/.

Singularity University. "Singularity University." August 9, 2016. https://su.org/ about/press-room/press-releases/singularity-university-addresses-the-worldsgreatest-challenges-at-su-global-summit/.

Smith, Bruce L. "Propaganda." Last updated April 18, 2017. https://www. britannica.com/topic/propaganda.

Sobota, Daniel J., Jana E. Compton, Michelle L. McCrackin, and Shweta Singh. "Cost of reactive nitrogen release from human activities to the environment in the United States." Environmental Research Letters 10, no. 2 (2015): 025006.

Steffen, Will, Katherine Richardson, Johan Rockstrom, Sarah E. Cornell, Ingo Fetzer, Elena M. Bennett, Reinette Biggs, et al. "Planetary boundaries: Guiding human development on a changing planet." Science 347, no. 6223 (2015): 1259855.

UNESCO. The United Nations World Water Development Report 2016. Perugia: UNESCO, 2016. http://unesdoc.unesco.org/images/0024/002440/24404le. pdf.

United Nations. Report of the Special Rapporteur on the right to food. New York: United Nations, 2017.

Wikipedia. "Wisdom." January 15, 2018. https://en.wikipedia.org/wiki/ Wisdom.

World Economic Forum. The Future of Jobs: Employment, Skills and Workforce Strategy for the Fourth Industrial Revolution. Geneva: World Economic Forum, 2016. http://www3.weforum.org/docs/WEF_Future_of_Jobs.pdf.

WWF. Living Planet Report 2016. Risk and resilience in a new era. Gland, Switzerland: WWF International, 2016. 
Open Access This chapter is licensed under the terms of the Creative Commons Attribution 4.0 International License (http://creativecommons.org/licenses/ by $/ 4.0 /$ ), which permits use, sharing, adaptation, distribution and reproduction in any medium or format, as long as you give appropriate credit to the original author(s) and the source, provide a link to the Creative Commons license and indicate if changes were made.

The images or other third party material in this chapter are included in the chapter's Creative Commons license, unless indicated otherwise in a credit line to the material. If material is not included in the chapter's Creative Commons license and your intended use is not permitted by statutory regulation or exceeds the permitted use, you will need to obtain permission directly from the copyright holder.



